\title{
Lipreading in the Prelingually Deaf: What makes a Skilled Speechreader?
}

\author{
Isabel de los Reyes Rodríguez Ortiz \\ Universidad de Sevilla (Spain)
}

\begin{abstract}
Lipreading proficiency was investigated in a group of hearing-impaired people, all of them knowing Spanish Sign Language (SSL). The aim of this study was to establish the relationships between lipreading and some other variables (gender, intelligence, audiological variables, participants' education, parents' education, communication practices, intelligibility, use of SSL). The 32 participants were between 14 and 47 years of age. They all had sensorineural hearing losses (from severe to profound). The lipreading procedures comprised identification of words in isolation. The words selected for presentation in isolation were spoken by the same talker. Identification of words required participants to select their responses from set of four pictures appropriately labelled. Lipreading was significantly correlated with intelligence and intelligibility. Multiple regression analyses were used to obtain a prediction equation for the lipreading measures. As a result of this procedure, it is concluded that proficient deaf lipreaders are more intelligent and their oral speech was more comprehensible for others.
\end{abstract}

Keywords: lipreading, prelingually deaf, deafness, oral speech

Se estudió el dominio de la labiolectura en personas sordas usuarias de la lengua de signos española. El objetivo era establecer las relaciones entre la lectura labiofacial y otras variables (género, inteligencia, variables audiológicas, nivel educativo del sujeto y de los padres, prácticas comunicativas, inteligibilidad de su habla y uso de la lengua de signos española). Los 32 sujetos de la muestra tenían edades comprendidas entre los 14 y los 47 años. Todos tenían pérdidas auditivas neurosensoriales (de severas a profundas). El procedimiento para evaluar la lectura labiofacial se basaba en la identificación de palabras aisladas. Estas palabras fueron emitidas siempre por el mismo evaluador. La identificación de las palabras se hacía a través de la selección entre cuatro alternativas. La lectura labiofacial correlacionó de manera significativa con la inteligencia y la inteligibilidad del habla. Se empleó un análisis de regresión múltiple para obtener una ecuación que permitiera predecir las puntuaciones en lectura labiofacial. Como resultado de este procedimiento se observó que los mejores labiolectores sordos fueron aquellos que eran más inteligentes y tenían un habla más inteligible.

Palabras clave: lectura labiofacial, prelocutivos, sordera, lengua oral

This investigation was conducted thanks to the funding received by the Ministerio de Educación y Ciencia, project summons I+D (SEJ2007-67080/PSIC) and by the Consejería de Innovación, Ciencia y Empresa de la Junta de Andalucía, via its incentive summons for Excellent Research Projects (P07-SEJ-02574). The author also wishes to thank Ana López Jiménez and David Saldaña Sage, Titled Professors of the Facultad de Psicología de Sevilla for their useful comments, as well as all the deaf people who participated in the study for their collaboration.

Correspondence concerning this article should be addressed to Isabel Rodríguez Ortiz, Departamento de Psicología Evolutiva y de la Educación, Facultad de Psicología, C/Camilo José Cela, s/n, 41018. Sevilla (Spain). E-mail: ireyes@us.es

Translator: Virginia Navascués Howard

How to cite the author of this article: Rodríguez Ortiz, I. 
The term "lipreading" refers to the "fact of seeing in the mouth of the person who is talking to us the words that we should normally hear" (Cecilia Tejedor, 2000, p. 20). Thus, it involves using an alternative modality to audition, the visual modality, to access oral speech. As the environmental noise or the loss of hearing increases, people resort to lipreading to compensate for the loss of auditory information.

But lipreading is not the best substitute of the auditory path (Bernstein \& Auer, 2003). The difficulties involved in this practice are familiar both to deaf people and the professionals who are in charge of their education. However, lipreading is also very beneficial when developing oral speech and facilitating integration in a society that is mostly made up of hearing people. For example, many authors state that children with hearing discapacity access the phonological code through lipreading, although they also use other sources of information such as their own articulation (Alegria, 1998; Alegria, Charlier, \& Mattys, 1999; Campbell, 1997; Campbell \& Burden, 1994; Dodd, 1980).

In contrast, although the access to phonological code provided by lipreading is incomplete (due to the difficulty to distinguish some phonemes on the lips), lipreading facilitates this access sufficiently to be able to observe a clear relation between the level of lipreading achieved by the deaf and their mastery of reading (Harris \& Moreno, 2006; Kyle \& Harris, 2006). Harris and Moreno even state that good lipreading is the trait that identifies all the good deaf readers, although they qualify this statement by adding that it is a necessary but insufficient condition to become a good reader.

But the main benefit provided by well developed lipreading is that it improves the reception and comprehension of oral speech, as it allows compensating for the information that is not correctly perceived through the auditory channel. This effect has been observed both in deaf and in hearing people (Schwartz, Berthommier, \& Savariaux, 2004).

However, despite this series of benefits associated with the practice of lipreading, this channel of access to information is clearly inferior to the auditory channel in its efficacy because lipreading is subject to a series of limitations that we shall comment on below.

The most important limitation of lipreading is that not all the phonemes that are heard can be perceived on the lips (for example, the velars). Some phonemes are perceived but are easily confused with others (for example, /p, b, and m/). In Spanish, according to the data on visual perception of speech presented by Perelló and Tortosa (1978), five groups of confusions can be distinguished between the consonant sounds: /d, t/; /m, p, b/; /s, r/; /k, g, j/ and /l, r/.

These groups of orofacial confusions coincide with those proposed by Cecilia Tejedor (2000), except that in this case, new groups are added, among which are included vowels. According to this author, the groups of sounds as a function of the difficulty involved in their perception on the lips would be: the group of the vowels and velars $/ \mathrm{a} /, \mathrm{o} /, \mathrm{l} /$, /e/, /i/, /g/, /j/, /k/; the group of the bilabials /p/, /b/, /m/; the group of the labiodental /f/; the group of the interdental sound corresponding to the letter $\mathrm{z}$, sometimes forming a group with /d/, mainly at the end of words; the group of the dentals $/ \mathrm{t} /$ and $/ \mathrm{d} /$; the group of the alveolars $/ \mathrm{l} / \mathrm{h} / \mathrm{n} /$ and $/ \mathrm{r} /$; the group of the palatals, that is, sounds corresponding to the letters $l l, c h, \tilde{n}$, and $y$, along with the alveolar $/ \mathrm{s} /$.

This difficulty to discern the different groups of phonemes causes their correct perception to range between 10 and 25\% (Woodward \& Barber, 1960) and the correct perception of isolated words to range between 10 and $30 \%$ (Rönnberg, Samuelsson, \& Lyxell, 1998). Within the phonemes, isolated consonants are more difficult to identify than isolated vowels, according to the comparison of different studies (Bernstein \& Auer, 2003).

Another limitation usually attributed to lipreading is that it depends on the distance between speakers. Specifically, a distance of between 50 centimeters and 3 meters is recommended to be able to lipread with comfort and precision (Cecilia Tejedor, 2000).

Lipreading also demands special conditions of luminosity and visibility. It cannot take place if the speaker places an object between his or her lips and the recipient's vision.

Lastly, another limitation of lipreading refers to its dependence on the context. Lipreading isolated phrases is extremely difficult when not supported by the context (approximately $5 \%$ of words in phrases are correctly identified, according to the results of Samuelsson \& Rönnberg, 1991, 1993).

In parallel to these external limitations are a series of individual variables that intervene in lipreading. The result of the bibliographic review of this issue is commented on below.

According to Conrad (1979), the capacity for lipreading seems to be determined by the person's degree of hearing and the levels of intelligence and of speaking. However, the studies that have focused on establishing the relation between the degree of hearing and the level of lipreading have not reached unanimous conclusions. Some have observed that hearing people are usually better lipreaders than deaf people and, therefore, they have concluded that the more the loss of hearing, the more difficult lipreading will be (Massaro, 1987; Mogford, 1987). However, authors like Arnold and Köpsel (1996) find no relation between these two variables and Bernstein, Demorest, and Tucker (2000) observe that deaf people identify phonemes in direct syllables and words, both isolated and in sentences, better than hearing people. Along these same lines, early onset of loss of hearing is observed to contribute to better lipreading, at least, when the loss of hearing is severe (Rönnberg, 1995; Tillberg, Rönnberg, Svärd, \& Ahlner, 1996).

Nevertheless, lipreading makes a higher cognitive demand than habitual auditory processing of oral information (Rönnberg et al., 1998). This is due to the fact that access to speech through lipreading depends on the person's 
deduction capacity. This capacity allows access to speech by mentally completing what the ear cannot hear or the eye perceive (Lyxell, 1994; Rönnberg, 1995). Therefore, it is considered that there is a clear relation between intelligence and lipreading, which leads some authors to indicate that, when the intelligence quotient is lower than 80 , there are important lipreading difficulties (Cecilia Tejedor, 2000). Yet the relation between intelligence and lipreading does not seem so clear to all authors, for example, for Silvestre and Laborda (1998). According to these authors, there is a correlation in the cases in which there is good mastery of lipreading; in contrast, there is no correlation in cases with insufficient mastery of lipreading. Thus, they conclude that intelligence may be necessary, but it is not sufficient to achieve a good level of competence in lipreading.

Deductive capacity is closely related to knowledge of lexicon and linguistic competence in general so that, ultimately, lipreading also depends on the lipreader's knowledge of oral speech (Conrad, 1979). Concerning this influence, there is the paradox that deaf children do not achieve good lipreading unless they have achieved an adequate level of global linguistic competence, and this is attained, among other ways, by lipreading. But lipreading does not seem to provide prelingual deaf children with easy acquisition of language. Only about 35\% of speech is accessed through lipreading (Torres, Urquiza, \& Santana, 1999). Despite this, the studies find that deaf subjects with higher mastery of oral speech perform at the same level of lipreading as hearing people and much better than bilingual (oral language and sign language) deaf subjects (Arnold \& Köpsel, 1996).

The fact that training in verbal articulation improves visual perception of speech is nothing new (Ling, 1976); this influence seems due to the fact that, according to the motor theory proposed by Liberman, Cooper, Shankweiler, and Studdert-Kennedy (1967), speech perception is facilitated as a result of people's knowledge about their own articulatory movements.

Phonological processing skills have also been shown to have significant impact on levels of lipreading (Conrad, 1979). As with written material, in lipreading, phonological processing also allows decoding the visual input and activating the corresponding lexicon and, in effect, it permits people whose phonological processing skills are more developed to become better lipreaders (Lyxell, Rönnberg, \& Samuelsson, 1994). Therefore, adequate development of phonological representations is an important prerequisite for lipreading skill in people with hearing deficiency (Rönnberg et al. 1998). Perhaps phonological processing mediates in the relation between reading and lipreading that has been observed in various studies (Arnold \& Köpsel, 1996; Bernstein, Demorest, \& Tucker, 1998), but this possible mediation requires more investigation.

Another factor considered to be related to successful lipreading is the capacity of the working memory (Lyxell
\& Rönnberg, 1989). The highest performances in lipreading are achieved when there are high levels of working memory capacity (Lyxell, 1994; Rönnberg, 1995), which leads to the conclusion that short-term memory capacity is an important component of the cognitive processes that underlie lipreading (Arnold \& Köpsel, 1996). Visual memory and sequential auditory memory are also positively related to lipreading, as shown by the studies of De Filippo (1982) and of Heider and Heider (1940, quoted in Arnold \& Köpsel, 1996).

The role that sign language may play in the development of lipreading is still unclear. According to some authors, signs hinder the development of oral speech and, therefore, of lipreading. It is thought that children who use sign language will not read lips because it will be easier for them to interpret signs than lip movements (González Cuenca, 1995). However, to date, neither this negative influence has been verified, nor the possible beneficial influence of certain sign parameters (facial expression, mouth gesture, lip movements) in the development of lipreading skill. From a review of the studies on lipreading in the prelingual deaf, Mogford (1987) concludes that whether the deaf child's education was carried out by means of oral speech or by manual communication seems to have no influence on this skill. Arnold and Köpsel (1996) find that mastery of sign language, assessed by teachers, does not correlate with lipreading, although it does correlate with reading, which, in turn, is positively correlated with lipreading $(r=.81, p=.005)$.

Another communication system that has received much attention in the research on lipreading is the cued speech. This is an incremental communication system whose main goal is to clarify the ambiguities of lipreading by means of the support of manual cues around the face (Torres \& Ruiz, 1996). Various authors in diverse languages (Nicholls \& Ling, 1982; Alegría et al., 1999) have observed that the cued speech increases the rates of visual speech perception when compared with other alternative or complementary systems of oral speech. In the Spanish language, Santana and Torres (2000) made this same comparison using five groups of participants, as a function of the communication system used: a purely oral deaf group, cued speech deaf group, bimodal deaf group, sign language deaf group, and control hearing group. The assessment task was to identify words and pseudowords. When the presentation modality was exclusively lipreading, the participants from all the groups discriminated words at the level of chance and, in the case of pseudowords, at very low levels. In the cued speech deaf group, when the presentation was made with this system, discrimination rose to $60 \%$ in the case of words (52\% with only lipreading) and the same occurred with pseudowords, where a slightly higher level of perception was observed than that achieved by mere lipreading, but the differences were not statistically significant. When the presentation combined cued speech and hearing, the levels of performance were much higher than those of the rest of the groups, reaching $100 \%$ in the case of words and $50 \%$ in the case of pseudowords. 
From the above, a very fragmented view of the factors that affect lipreading performance is obtained. On the other hand, taking into account that this path of access to language is the main one in severely deaf people who have no technical aid to improve their hearing, it is necessary to study the factors that are related to better lipreading performance in this population. The study of Bernstein et al. (2000) was aimed at this goal. In this investigation, 72 students, ages between 18 and 41 years, from the University of Gallaudet participated, all of them with sensorineural hearing losses higher than $65 \mathrm{~dB}$ in the better ear. Of them, $66 \%$ presented congenital hearing deficiency and $23 \%$ had acquired the loss between 2 months and 3 years of age, that is, most of the participants were prelingual deaf. The assessment task of the lipreading level consisted of identifying phonemes in direct syllables, words, and sentences. More than 29 variables of the audiological factors, the parents' educational level, communication practices at home and in public, self-perception of the skill to understand oral speech, self-perception of the degree of intelligibility of oral speech, and reading and writing performance, assessed by means of the English Placement Test of the University of Gallaudet, were examined. Of all the variables examined, the ones that were shown to be the most closely related to lipreading isolated words was the years gone by since the last audiphone used $(r=-.30, p<.05)$, the use frequency of audiphones $(r=.36, p<.001)$, communication at home through oral speech $(r=-.58, p<.001)$, communication at home through gestures or family signs $(r$ $=.45, p<.001)$, communication in public through oral speech $(r=-.26, p<.05)$, communication in public by writing $(r=.30, p<.05)$, communication in public by gestures or family signs $(r=.33, p<.001)$, perceived capacity to understand oral speech of hearing friends and relatives $(r=-.30, p<.05)$, perceived capacity to understand oral speech of the general public $(r=-.40, p<.001)$, perceived capacity to be understood by hearing friends or relatives when using oral speech $(r=-.39, p<.001)$, perceived capacity to be understood by the general public when using oral speech $(r=-.49, p<.001)$, and reading level $(r=.35, p<.001)$. Neither onset age of loss of hearing nor the parents' educational level, nor the use of sign language, nor the use of dactylology or the bimodal program were related to any of the measures of lipreading performance. After regression analysis of the results, these authors concluded that the best deaf lipreaders were those who understand the general public's speech, use oral speech at home, and are better readers of written material; that is, the best lipreaders are the ones who better understand and use oral speech.

The study of Bernstein et al. (2000) was carried out in the English language, a language that is much more obscure than Spanish when discriminated on the lips. Therefore, it is interesting to determine whether the factors that affect lipreading of deaf people in the English language are the same as in Spanish and this investigation was proposed to address this issue.

Another reason for this project is that the study of the factors related to mastery of lipreading has practical consequences in the educational setting in which people with hearing discapacity grow up. For example, it helps to decide whether the students have the necessary prerequisites to achieve a good level of lipreading or whether it is better to try other pathways of access to information. It also serves to support the decisions taken about the design of training programs in lipreading. Therefore, an investigation about the factors that are related to mastery of lipreading such as the one presented in this article is relevant.

This study aims to determine which variables affect lipreading performance in a transparent orthographic language such as Spanish in a sample of deaf people. Specifically, the investigation has the following goals:

1. To describe the performance of lipreading isolated words in a group of prelingual deaf people using an instrument designed for this purpose.

2. To determine the variables associated with better lipreading mastery in a sample of prelingual deaf people.

\section{Method}

\section{Participants}

The sample was mainly selected through the associations of deaf people in three Spanish cities (Seville, Cadiz, and Huelva) and comprised 32 prelingual deaf people (19 male and 13 female), mean age 26.75 years $(S D=7.94$; minimum 14 and maximum 47 years).

All the participants had neurosensory deafness, with no other associated discapacities. Thirteen of these hearing deficiencies were severe, and 19 profound, according to the classification of the Bureau Internacional d'Audiophonologie (that is, taking as reference the mean loss of hearing for the frequencies of 250,500 , and $2000 \mathrm{~Hz}$ ). The mean age at the onset of loss of hearing was 0.46 years $(S D=0.91$; minimum 0 years, and maximum 3). As for etiology, 14 of the losses of hearing were hereditary, 15 acquired, and 3 of an unidentified cause.

Of the sample, $81 \%$ (26 people) had only studied primary education and 19\% (6 people) secondary education.

With regard to the communication system, all the participants knew the Spanish sign language (SSL), but it was the family language of only one person from the sample. However, 22 of the 32 participants of the sample considered that sign language was their most usual means of communication, whereas the rest used oral speech as the most frequent communication system.

The mean score in intellectual quotient, measured by Raven's Progressive Matrixes, was 105.3 ( $S D=12.4$; maximum 123, minimum 72). 


\section{Instruments}

A lipreading assessment test was elaborated to achieve the above goals. The purpose of the material designed was to ensure that the participants' responses were exclusively due to lipreading, that is, they were not deduced from the context. For this purpose, prints with simple images with names that included all the phonemes in Spanish (see the recording sheets in the appendixes) were used. The degree of frequency of the words used was similar, according to the frequency dictionaries of Justicia (1995) and Alameda and Cuetos (1995); however, it was not always possible to find such homogeneity among word frequencies when all the sounds of the Spanish language were supposed to be represented, and also three different difficulty levels of word discrimination were established.

Each print included four images with their corresponding written word below. In this way, it was ensured that the participant had to think of the word whose lipreading was being assessed and not any other word suggested by the image.

The prints were divided into three levels of lipreading difficulty:

1. Level 1: in each print, there were four images of words of different lengths insofar as number of syllables, and different phonemes, for example, images of pan ${ }^{1}$, teléfono, cronómetro, and huevo (the word pan, which is the word the participant must indicate, is emitted).

2. Level 2: in each print, there were four images of words of the same length insofar as number of syllables, but with different phonemes, for example, images of lata, pera, piso, and cazo (the word lata, which is the word the participant must indicate, is emitted).

3. Level 3: in each print, there were four images of words with of same length insofar as number of syllables, and with all the same phonemes except for one (i.e., pala, polo, pela, and pila).

According to Conrad (1979), a high score in a lipreading test may either indicate that the person has a good level in this capacity or that the text is excessively easy. I think the latter possibility can be ruled out with the inclusion of Level 3 of the test, as this demands a high level of discrimination.

On the other hand, one of the variables examined in this study because of its relation to lipreading is speech intelligibility. Such speech intelligibility was assessed by two tests. Test 1, "intelligibility of isolated words," consisted of pronouncing words that had all the phonemes of Spanish and, for this purpose, I used the cards with images from the audiematic discrimination test of Gómez Fernández (1985). Test 2, "intelligibility of words in context," consisted of assessing the speech intelligibility in a discourse and, for this purpose, I requested the participants to describe a drawing corresponding to a story. Specifically, the oral emission was elicited from a scene in a Roman camp, taken from a comic book of Asterix and Obelix. It represented various related actions from daily life, so it was possible to make two types of comment about the print: list the people, animals, and objects that appeared in the print performing various actions, and describe the scene in which some actions were associated with others, forming a more compact discourse.

\section{Procedure}

So that the verbal production would not interfere with the variable assessed (lipreading), the participants' verbal responses were minimized by requesting them to perform a motor action: they should indicate on the prints the image that corresponded to the word they were lipreading.

Another variable controlled was the number of assessors. Lipreading can be easier or more difficult depending on the speaker (Conrad, 1979), but, in this case, the same assessor was the speaker for all participants. I also chose the direct presence of the assessor instead of a video recording because, according to Berger (1972), real presentation enhances lip discrimination more than an image on a screen.

At all levels of discrimination, the print with the four images was placed in front of the participant. The assessor sat in front of the participant, at a distance of about one meter and at the same height as the participant's face. The assessor vocalized, without sound, each one of the words, leaving enough pause between them for the participant to indicate the corresponding drawing on the print and for the assessor to record the response. The assessor's mouth was free from obstacles and the vocalization was done at a normal speed and in adequate luminosity conditions.

I decided to use vocalization without sound for each word to avoid the influence of auditory remains and/or prothetic aids of the participants. The goal of the task was to assess the capacity of analysis and visual perception involved in lipreading and not so much the participants' ability to extract information from the interlocutors by lipreading and from their auditory remains.

For each level, a practice item was used at the beginning of the test and feedback was provided to ensure that the participants had understood the procedure. During the test itself, no feedback was provided. If necessary, another test item could be added. Both test items appeared on the

1 Translator's note: none of the words in Spanish used in the prints has been translated because the article is about lipreading in the Spanish language. What is relevant is not the meaning of the words, but their sounds. 
recording sheet in the first two rows (see appendixes). The presentation order of the words was the one established on the recording sheet.

Instructions were provided both in oral speech and in sign language (depending on the participants' communicative preferences). The test was presented individually and the instructions were as follows: "Look at these prints. I am going to pronounce a word and you should indicate the corresponding image, for example, if I say joya, what image would you point to?" (The assessor waits until the participant points to the image, and if he/she did not do so, then the assessor provides the response and selects another practice item). The words could be repeated up to three times if the participant so required, both during the practice trials and during the procedure, but as very few participants requested repetition and on very few occasions, this variable was not taken into account in the subsequent statistical analysis.

In the recording sheet, for each print, the number of hits was counted and written in the corresponding column. Later, the total score was calculated by adding the hits in each print.

Likewise, for each print, in the column of the types of errors, the mistakes were noted as follows: " $1 \rightarrow 2$ "; this means that the first word of the print was pronounced and the participant pointed to the second one.

Regarding the appraisal of speech intelligibility, both the intelligibility of isolated words and of words in context were assessed by three independent judges. In the first case, they gave 1 point to each one of the correctly articulated words and in the second case, the oral emission was classified on a 5-point scale ranging from 0 (no significant emissions), 1 (incomprehensible), 2 (interpretable for familiar interlocutors), 3 (comprehensible with the help of contextual references), 4 (comprehensible with no need for contextual references).

\section{Results}

Nonparametric tests were used for the statistical analysis because of the nature of the data. Specifically, I used MannWhitney's $U$, Kruskal-Wallis, and Kendall's Tau-b.

\section{Global Level of Lipreading of Isolated Words}

At levels 1 and 2, the entire sample responded correctly to all the items, so the mean number of hits was 23 in both cases $(S D=0)$, that is, the maximum possible score. Either one of the two alternatives proposed by Conrad (1979) to explain this (the participant has a good level in this capacity or else the test is excessively easy) could justify the high score obtained at these two levels by all the participants of the sample. In any case, levels 1 and 2 did not allow me to discriminate the degree of mastery of lipreading.
Level 3 of lipreading allowed more variability among the participants. the mean was 65 hits $(S D=5.9$, minimum 48 and maximum 74); that is, taking into account that the maximum score that could be obtained at this level was 80 , the sample examined was capable of correctly solving $81.25 \%$ of the isolated words presented.

\section{Most Frequent Errors in the Discrimination of Phonemes in Isolated Words}

In Table 1 are displayed the results obtained regarding the percentage of participants who correctly lipread each one of the words and the percentage of participants who committed the most frequent error in each word. The first thing that the analysis of this table emphasizes is that, in accordance with previous studies carried out in the English language (Montgomery \& Jackson, 1983; Owens \& Blazek, 1985), vowels are easier to discriminate on the lips than consonants. The percentage of participants who correctly identified vowels ranged between a minimum of $50 \%$ and a maximum of $100 \%$, whereas for consonants, it was $28.1 \%$ and $100 \%$, respectively. However, if the hits for the two groups of sounds are compared, the differences did not reach statistical significance, $U(85)=1.060 ; p=.303$.

The mean number of hits obtained in the vowel group, taken globally, was $27.95(S D=4.35) ; M=27(S D=5.59)$ for $/ \mathrm{a} / ; M=26.20(S D=6.22)$ for $/ \mathrm{e} / ; M=29(S D=2.16)$ for $/ \mathrm{i} / ; M=28.6(S D=3.5)$ for $/ \mathrm{o} /$; and for $/ \mathrm{u} / M=29.67$ $(S D=4.04)$. Among the vowels, the most frequent confusion was between /e/ and /i/. Of the 16 prints in which contrasts of vowels were presented, in 6 of them, the most frequent error was confusing /e/ and /i/ and, especially, in the case of the discrimination of the words tela and tila, which were confused by one half of the participants of the sample. Nevertheless, when a statistical contrast between the rates of hits of each one of the vowels was performed, no significant differences were found, $H(4,21)=1.537$, $p=.820$.

In the group of consonants, the mean number of hits was $25.30(S D=7.03)$. In the consonants, the percentage of people who made mistakes was higher than the hit percentage in the following cases: pino confused with vino, pasa confused with masa and vice versa, gota confused with jota and vice versa, corro confused with gorro and vice versa. When I compared the hit rates obtained in each one of the groups indicated by Cecilia Tejedor (2000) as a function of the difficulty they generate for lipreading $(/ \mathrm{a} /$, $/ \mathrm{o} /, / \mathrm{u} /, / \mathrm{e} /, / \mathrm{i} / ; / \mathrm{g} /, / \mathrm{j} /, / \mathrm{k} / ; / \mathrm{p} /, / \mathrm{b} /, / \mathrm{m} / ; / \mathrm{f} / ;$ the sound corresponding to the letter $z ; / \mathrm{t} /$ and $/ \mathrm{d} / ; / \mathrm{l} /, / \mathrm{n} /$ and $/ \mathrm{r} /$; the sounds corresponding to the letters $l l, c h, \tilde{n}$, and $y$, along with the alveolar $/ \mathrm{s} /$ ), significant differences were noted between them, $H(7,84)=20.734, p=.004$, but, specifically, the group of the sounds $/ \mathrm{g} /, \mathrm{j} /, / \mathrm{k} /$ generated a lower number of hits when compared with the remaining groups (see Table 2): $U(30)=12.500, p=.000$ when this group was compared 
Table 1

Most Frequent Errors in the Discrimination of Phonemes in Isolated Words of Level 3

\begin{tabular}{|c|c|c|c|c|}
\hline Print & Image 1 & Image 2 & Image 3 & Image 4 \\
\hline 1 & Pala (87.5) / Pela (6.3) & Polo (100) & Pela (78.1) / Pila (21.9) & Pila (87.5) / Pela (12.5) \\
\hline 2 & Tela (50) / Tila (50) & Tala (59.4) / Tela (28.1) & Tila (84.4) / Tela (12.5) & Tula (100) \\
\hline 3 & Poro (96.9) / Puro (3.1) & Pero (96.9) / Paro (3.1) & Puro (100) & Paro (100) \\
\hline 4 & Muro (78.1) / Moro (18.8) & Mero (87.5) / Miro (9.4) & Moro (87.5) / Muro (12.5) & Miro (90.6) / Mero (9.4) \\
\hline 5 & Vino (46.9) / Pino (28.1) & Pino (43.8) / Vino (46.9) & Fino (90.6) / Vino. Pino. Chino (3.1) & Chino (96.9) / Pino (3.1) \\
\hline 6 & Casa (75) / Gasa (25) & Gasa (78.1) / Casa (21.9) & Pasa (40.6) / Masa (59.4) & Masa (40.6) / Pasa (56.3) \\
\hline 7 & Chilla (59.4) / Silla (40.6) & Silla (68.8) / Chilla (31.3) & Villa (93.8) / Pilla (6.3) & Pilla (93.8) / Villa (6.3) \\
\hline 8 & Ducha (96.9) / Trucha (3.1) & Lucha (93.8) / Hucha (6.3) & Hucha (93.8) / Lucha (6.3) & Trucha (96.9) / Ducha (3.1) \\
\hline 9 & Nada (90.6) / Nata (9.4) & Napa (96.9) / Nada (3.1) & Narra (96.9) / Nata (3.1) & Nata (93.8) / Nada (6.3) \\
\hline 10 & Fuego (96.9) / No responde (3.1) & Zueco (100) & Hueco (65.6) / Cuenco (34.4) & Cuenco (62.5) / Hueco (37.5) \\
\hline 11 & Gota (28.1) / Jota (71.9) & Jota (31.3) / Gota (68.8) & Bota (100) & Sota $(100)$ \\
\hline 12 & Joya (59.4) / Goya (25) & Goya (65.6) / Joya (21.9) & Boya (100) & Olla (71.9) / Joya (15.6) \\
\hline 13 & Lave (71.9) / Nave (25) & Llave (96.9) / Lave (3.1) & Nave (81.3) / Lave (15.6) & Ave (90.6) / Lave (9.4) \\
\hline 14 & Lloro (93.8) / Loro. Oro (3.1) & Loro (90.6) / Oro (6.3) & Moro (96.9) / Oro (3.1) & Oro (90.6) / Loro (9.4) \\
\hline 15 & Nata (56.3) / Lata (28.1) & Lata (87.5) / Nata (12.5) & Mata (100) & Rata (87.5) / Nata (9.4) \\
\hline 16 & Piña (87.5) / Pita (12.5) & Pila (100) & Pita (90.6) / Piña (6.3) & Pipa (100) \\
\hline 17 & Pisa (53.1) / Visa (31.3) & Misa (71.9) / Pisa (18.8) & Visa (93.8) / Pisa (6.3) & Risa (100) \\
\hline 18 & Pera (84.4) / Pela (9.4) & Perra (75) / Peña (18.8) & Pela (96.9) / Pera (3.1) & Peña (100) \\
\hline 19 & Asa (50) / Hacha (46.9) & Hacha (62.5) / Asa (31.3) & Ata (75) / Asa (21.9) & Ala (100) \\
\hline 20 & Zorro (100) & Corro (34.4) / Gorro (65.6) & Gorro (40.6) / Corro (59.4) & Forro (100) \\
\hline
\end{tabular}

Note. In each cell, the percentage of hits and errors of lipreading a word is recorded according to the following presentation: emitted word (percentage of hits) / most frequent error (percentages of misses).

with the group of /a/, /o/, /u/, /e/, /i/; $U(25)=28.000, p=$ .012 when compared with the group of $/ \mathrm{p} /, / \mathrm{b} /, / \mathrm{m} / ; U(12)$ $=0.000, p=.009$, when compared with $/ \mathrm{f} / ; U(11)=0.000$, $p=.036$ when compared with the sound corresponding to $z ; U(14)=1.500, p=.002$ when compared to the group of $/ \mathrm{t} /$ and $/ \mathrm{d} / ; U(23)=8.500, p=.000$ when compared with the group of $/ 1 /, / \mathrm{n} /$ and $/ \mathrm{r} / ;(23)=25.000, p=.016$ when compared with the group of the sounds corresponding to the letters $l l, c h, \tilde{n}, y$, and $s$.

Familiarity with the words did not seem to be an important factor to discriminate them visually, as the fact that low frequency words such as Tula, tila, mero, gasa,

Table 2

Difficulty in Lipreading (Level 3) as a Function of the Group of Sounds (Means and Standard Deviations of Hits)

\begin{tabular}{lll}
\hline Sounds corrresponding to & $M$ & $S D$ \\
\hline A, e, i, o, u & 27.95 & 4.35 \\
G, j, k & 16.89 & 6.19 \\
P, b, m & 25.25 & 7.89 \\
F & 30.67 & 1.53 \\
Z & 32 & 0 \\
T, d & 28.6 & 2.7 \\
L, n, r & 28.14 & 4.05 \\
Ll, ch, n, y, s & 24.64 & 6.74 \\
\hline
\end{tabular}

villa, napa, zueco, sota, boya, nave, visa and peña were recognized on the lips by the majority of the participants without any trouble (the frequency of Tula, mero, napa and visa does not even appear in the frequency dictionary of Justicia, 1995, and the frequencies of the remaining words were as follows: tila $=4$, gasa $=6$, villa $=6$, zиесо $=2$, sota $=3$, boya $=2$, nave $=41$, and peñ $a=1$ ). According to the dictionaries of Justicia (1995) and Alameda and Cuetos (1995), when the correlation between the frequencies assigned to the words and the number of hits is calculated, no significant relation was obtained: $\vartheta(68)=-.022 ; p=$ .802 in the dictionary of Justicia and $\vartheta(76)=.012 ; p=.882$ in that of Alameda and Cuetos). Nevertheless, this statement requires a study dedicated particularly to elucidate this issue.

\section{Variables Associated with Lipreading Mastery}

In this section, I examine the variables from the bibliographic review of the topic that have been noted to have the most influence on lipreading. Taking into account that all the participants of the sample correctly responded to all the items from lipreading difficulty Levels 1 and 2, I shall focus on the analysis of the factors that affect this skill at Level 3.

Gender. In the case of hearing people, women have been observed to score higher in lipreading than men (Dancer, 1994). However, the variable gender has not been shown to 
affect lipreading in the group of deaf people either in any of the studies examined, or in this study. The results indicate that there are no gender differences in lipreading performance, $U(32)=135.500, p=.440$. The mean number of hits both for men and women was $65(S D=4.75$ and $S D$ $=7.5$, for the group of 19 men and 13 women, respectively).

Intelligence. In this study, I observed a positive and significant correlation between lipreading and the level of intelligence, $\vartheta(32)=.391 ; p=.001$, coinciding with the findings of Silvestre and Laborda (1998), although the correlation was not very high.

Loss of hearing. As reported in the study of Arnold and Köpsel (1996), no significant differences were observed as a function of the degree of loss of hearing, $U(32)=127.000$, $p=.607$. The participants with severe losses had a mean lipreading score of $64.15(n=13, S D=5.41)$ and the participants with profound losses had a mean of $65.58(n=$ $19, S D=6.30)$.

According to the etiology of the loss of hearing, no differences were observed in the level of lipreading developed, $H(2,32)=1.316, p=.518$. The participants with hereditary deafness reached a mean of $65.79(n=14, S D=4.98)$, those with acquired deafness had a mean score of $63.87(n=15$, $S D=6.57)$ and those with auditory deficiency of unknown origin had a mean score of $67(n=3, S D=7.55)$.

Age at the onset of loss of hearing. In accordance with the results found by Bernstein et al. (2000), there was no correlation between the level of lipreading and age at the onset of the loss of hearing, $\vartheta(32)=.197, p=.134$.

Examining separately the relation of age at the onset of the loss of hearing and the lipreading level in the group of severely deaf people on the one hand, and of profoundly deaf people on the other, no significant correlations were observed, $\vartheta(13)=.215 ; p=.310$, for severe hearing deficiency; and $\vartheta(19)=.178 ; p=.346$, for profound hearing deficiency.

Likewise, when two groups-congenital (onset of auditory deficiency at birth), and later (onset at any time up to the age of 3) -were formed as a function of onset age of hearing loss, no significant group differences were observed in the number of hits when lipreading, $U(32)=$ $107.000, p=.920$. In the congenitally deaf $(n=22)$, the mean lipreading score was $64.64(S D=6.69)$, and in the case of people with later deafness $(n=10)$, the mean was $65.8(S D=3.8)$.

Use of audiphones. When dividing the sample into two groups as a function of audiphone use, those who never use it $(n=23)$ and those who use it daily $(n=8)$, no differences in lipreading performance as a function of this variable were found, $U(31)=73.000, p=.411$ The former obtained a mean score of $64.30(S D=6.34)$ and the latter of $66.75(S D=$ 4.71). This datum does not coincide with that found by Bernstein et al. (2000) in their study.

Educational level. No significant differences were observed as a function of participants' educational level,
$U(32)=50.500, p=.189)$. Nevertheless, it must be taken into account that the group of participants with secondary studies was made up of only 6 people and perhaps with a larger sample, the differences would reach statistical significance. The mean lipreading score obtained by the group with secondary studies was $67.83(n=6, S D=2.56)$ and that of the group with primary studies was $64.35(n=$ $26, S D=6.29$ ).

Regarding the father's educational level, although lipreading performance increased as a function of the paternal educational level (in the case of primary studies, $M=62.80$, $S D=5.02$; for secondary studies, $M=65.60, S D=6.39$, and for postsecondary studies, $M=69, S D=0$ ), it must be taken into account that only 16 participants of the entire sample responded about their father's educational level and, of them, only 1 participant said his/her father had postsecondary studies. When comparing the participants whose fathers had primary studies $(n=10)$ and those whose fathers had secondary studies $(n=5)$, the result was not significant, $U(15)=17.000, p=.371$, but the subgroups were still very small.

Regarding the influence of the mothers' educational level, the same can be said as about the fathers'. In this case, 17 participants responded, and it was observed that, when the mother only had primary studies, the participants' level of lipreading reached a mean of $64(S D=5.56)$, when she had secondary studies, lipreading mastery had a mean of 60.5 $(S D=0.71)$, whereas if the mother had postsecondary studies, the mean rose to 69 . Nevertheless, it must be noted that only 1 participant of the sample was in this last condition and only 2 participants said their mother had secondary studies, which means that this result is not conclusive.

Use of oral speech in diverse settings. The frequency of the use of oral speech in the family setting did not produce any difference in lipreading performance, $U(32)=38.000$, $p=.760$, as shown in Table 3 . The same occurs with the use of oral speech with friends, $U(32)=96.500, p=.457$, and at school or at work, $U(28)=77.500, p=.363$.

Regarding the influence of speech intelligibility, the scores obtained in the test of intelligibility of isolated words correlated positively and significantly with those obtained in lipreading, $\vartheta(32)=.281 ; p=.027$. Intelligibility of words in context was not significantly related to lipreading, $H(3$, $32)=2.325, p=.508$, although, as shown in Figure 1, most speech intelligibility in context tended to coincide with the highest scores in lipreading. Thus, the 2 participants whose speech was incomprehensible only reached a mean of 58 in lipreading $(S D=14.14)$, the 10 participants whose speech was only interpretable for familiarized interlocutors obtained a mean score of $64.10(S D=5.19)$, the 12 participants whose speech was comprehensible with contextual support had a mean of $65.25(S D=5.59)$, and the 8 remaining participants, whose speech was comprehensible without contextual reference had a mean of $67.5(S D=4.44)$. 
Table 3

Lipreading (Level 3): Hits as a Function of the Setting of Using Oral Speech

\begin{tabular}{llccc}
\hline Setting & Use Frequency & $n$ & $M$ & $S D$ \\
\hline Family & Never or very seldom & 3 & 66.67 & 3.05 \\
& Quite frequently or always & 29 & 64.83 & 6.14 \\
With friends & Never or very seldom & 21 & 64.43 & 6.10 \\
& Quite frequently or always & 11 & 66.09 & 5.64 \\
At school or work & Never or very seldom & 19 & 64.32 & 6.30 \\
& Quite frequently or always & 13 & 66.00 & 5.35 \\
\hline
\end{tabular}

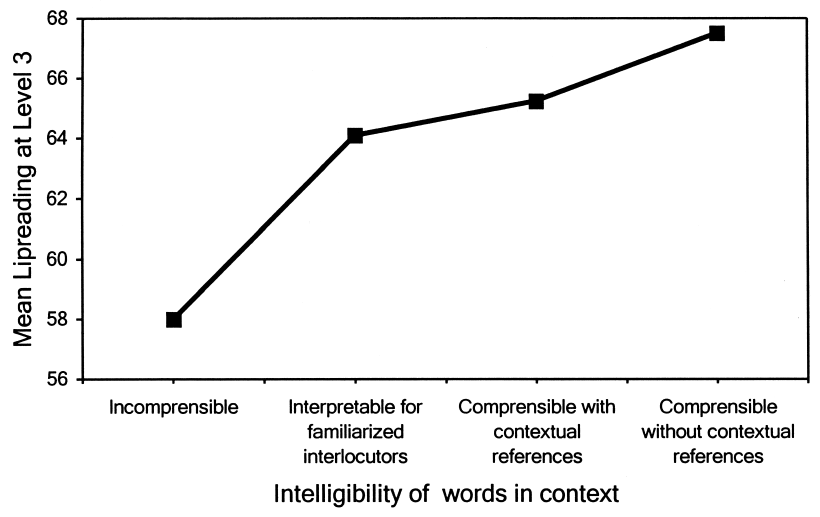

Figure 1. Mean score in lipreading of Level 3 difficulty as a function of the intelligibility of words in context.

Use of Spanish sign language (SSL). The frequency of use of SSL in the family setting was not significantly related to lipreading of isolated words, $H(4,32)=3.864$, $p=.425$, but it should be taken into account that, as the sample comprises deaf people who use sign language, only 4 participants reported that they never or very seldom used SSL with their family (see Table 4). This group presented a lower mean hit than that of the group of participants who used SSL very frequently in the family setting $((M=62, S D=9.66$, and $M=65.43, S D=5.30$, respectively).
The use of SSL at school or at work, $H(4,32)=1.799$, $p=.615$, did not produce significant differences in lipreading, despite which, as seen in Table 4 those who used it more frequently in this setting had higher scores than those who practically never used SSL $(M=66.57, S D=$ 5.57 , and $M=63.78, S D=6.02$, respectively).

With regard to the use of SSL with friends, no significant differences were observed, $H(4,32)=6.866, p=.143$, although in Table 4 , it can be noted that the participants who used this means of communication more frequently with their friends obtained higher scores in lipreading than those who barely use it in this setting $(M=67.82, S D=$ 4.75 , and $M=63.52, S D=6.01$, respectively). In short, in the three settings (family, school or work, and with friends), the participants who used SSL more frequently presented more mastery in lipreading, although the differences did not reach statistical significance.

However, when comparing the participants who considered SSL to be their most frequent communication system with those who considered it to be oral speech, the differences were not statistically significant either, $U(32)=$ $90.500, p=.434$. The former had a mean of 64.5 hits $(n=$ $22, S D=6.27)$, and the latter of $66.10(n=10, S D=5.15)$.

Of the other variables related to SSL, such as age when learnt $(\vartheta(32)=.084 ; p=.521)$, number of years of experience with this language $(\vartheta(32)=.086 ; p=.504)$, and the place where it was learnt (family, association, friends, school) $(H(3$, $32)=6.214, p=.102)$, none were related to lipreading.

Table 4

Lipreading (Level 3: Hits): Hits as a Function of the Setting of Use of Sign Language

\begin{tabular}{lllll}
\hline Setting & Use Frequency & $n$ & $M$ & $S D$ \\
\hline Family & Never or very seldom & 4 & 62.00 & 9.66 \\
& Quite frequently or always & 28 & 65.43 & 5.30 \\
With friends & Never or very seldom & 21 & 63.52 & 6.01 \\
& Quite frequently or always & 11 & 67.82 & 63.78 \\
At school or work & Never or very seldom & 18 & 66.57 & 1.42 \\
& Quite frequently or always & 14 & & 1.49 \\
\hline
\end{tabular}




\section{Regression Analysis}

I applied multiple regression analysis, with the method Enter, to obtain a predictor equation of lipreading. The variables selected for this purpose were the ones that had been shown to have a significant correlation with lipreading (level of intelligence and level of intelligibility of isolated words). The inclusion of the coefficients that reached significance led to an equation with coefficients for the two factors $\left(R=.577, R^{2}=.333\right)$ :

1. Intelligibility of isolated words (beta coefficient $=$ .113 , standardized beta coefficient $=.369$ ) .

2. Intellectual level (beta coefficient $=.164$, standardized beta coefficient $=.345$ ).

$R^{2}$ can be interpreted as an estimation of the proportion of explained variance of the measurement of lipreading. In this case, $33.33 \%$ of the variance of the variable lipreading was predicted by the variables intelligibility of isolated words and intellectual level (standard estimation error $=$ 4,988). Snedecor's $F$ statistic revealed a significant linear relation between the dependent variable and the set of independent variables, $F(2,29)=7.248, p=.003$. The standardized beta coefficients were all of comparable magnitudes and suggested that each one of the factors included to determine the coefficients contributed equally to the prediction of the lipreading scores. The $t$ contrast of the table of coefficients showed that both coefficients were significant ( $p<.05$ for both variables). In sum, correct word articulation contributed the same to the equation as intellectual quotient. The best lipreaders of this population were the ones whose speech was more intelligible and who had a higher intelligence level.

\section{Discussion and Conclusions}

From the above results, I obtained a high percentage of success in lipreading of isolated words (generally speaking, $81.25 \%$ of the words at the highest level of difficulty, and $100 \%$ in the remaining levels). This percentage amply exceeds the one found in other studies (Woodward \& Barber, 1960; Rönnberg et al., 1998; Santana \& Torres, 2000). I attribute this large difference to the fact that, in this investigation, the participants received contextual support provided by the images and written words that were included in the prints, and also to the fact that the lipreading was performed in a phonologically simpler language than the English language (in which most of the studies examined were carried out).

In this study, I observed that most confusions in lipreading were produced between the phonemes of the first group detected by Cecilia Tejedor (2000)—specifically, /e/, /i/, /g/, /j/ and / / $/$ - and the group of bilabials—/p/, /b/ and $/ \mathrm{m} /$-although the highest number of errors occurred significantly with the sounds $/ \mathrm{g} /, \mathrm{j} /$ and $/ \mathrm{k} /$.
With regard to /e/ and /i/, the confusion seems due the fact that they are both front vowels. Both $/ \mathrm{p} /$ and $/ \mathrm{b} /$ are bilabial phonemes that are lipread identically, as occurs with $/ \mathrm{p} /$ and $/ \mathrm{m} /$. In the case of $/ \mathrm{g} /$ and $/ \mathrm{j} /$, they are both sounded and, although /g/ is linguovelar and / $\mathrm{j} /$ is linguopalatal, they coincide in that they are both guttural sounds that are difficult to detect on the lips because their articulation point is not peripheral. The same holds for the confusion between $/ \mathrm{k} /$ in corro and /g/ in gorro, in which, moreover, both coincide in that they are occlusive and linguovelar.

Regarding the variables associated with lipreading, intelligence is shown to be positively correlated. However, coinciding with Silvestre and Laborda (1998), I think that intelligence seems to be a necessary but not sufficient variable for good lipreading to occur, because the degree of speech intelligibility also plays a role in high lipreading mastery.

The degree of loss of hearing revealed no significant differences in lipreading performance, as noted in other studies (Arnold \& Köpsel, 1996). However, it should be noted that, in this investigation, I did not use participants with slight and moderate loss of hearing, or hearing people, who might obtain different scores from the participants' and, therefore, might lead to the observation of a relation between this variable and lipreading.

Nor did age at the onset of loss of hearing correlate with the level of lipreading, in accordance with the results found by Bernstein et al. (2000). But it should be taken into account that, in this study, the loss of hearing appeared between 0 and 3 years of age, that is, with very little variability margin to allow the observation of significant differences due to this variable. The same thing can be said about the absence of differences due to age at onset of loss of hearing when the sample was divided into congenitally deaf and later deaf. Although the auditory stimulation received during the first 3 years of life is considerable and, therefore, group differences could have been foreseen, it should not be forgotten that both groups were made up of prelingual deaf people and, in these groups, the onset of deafness before consolidating oral speech seems to be a more relevant factor than the exact moment of onset of the hearing deficiency at this early stage. As there was no sample of postlingually deaf people, this study could not determine the influence of this variable on lipreading level.

Neither the participants' nor their parents' educational level produced any significant differences; however, I observed a tendency of a relation between the highest educational levels and better lipreading scores, which a study with a larger sample, or at least a sample whose participants would report their parents' level of studies, might confirm.

Although it produced no statistically significant differences in these results, the variable exposure to oral speech caused the participants who used oral speech the most in the educational and/or work setting to obtain higher scores in lipreading. Nevertheless, from these data, it cannot be derived that the best educational option to enhance lipreading is 
intensive and exclusive exposure to oral speech, because mere lipreading of isolated words, no matter how good, does not guarantee access to knowledge and, anyhow, it will always be necessary to value the circumstances that converge in every student with hearing discapacity when selecting the preferred communicative modality to develop their learning.

Another variable that has proved to be related to lipreading is the participants' speech intelligibility. This correlation was shown to be significant in the case of intelligibility of isolated words, but not in words in context. Regarding the latter, the relation is clear, but not significant. These data coincide to some extent with those found by Bernstein et al. (2000), although, in this case, speech intelligibility was measured globally via participants' selfappraisal of the degree to which they thought that others understood them. This also supports the motor theory of speech perception of Liberman et al. (1967).

With regard to the use of SSL, the investigation did not obtain any clear result that supports its influence, either positive or negative, on the level of lipreading. The use of SSL in the interactions with friends, at home, and at school and/or work settings is positively related to lipreading of isolated words, but this influence was not statistically significant. From these results, perhaps it could be concluded that participants whose communication (either via SSL or oral speech) in the diverse settings is more reinforced achieve the highest levels of lipreading, but in order to verify this statement, a study specifically dedicated to this is required.

From the results of this investigation, it is concluded that the best lipreaders among prelingual deaf people are those with a higher level of intelligence and more intelligible speech.

Other variables examined, such as gender, the type and degree of loss of hearing, and the age at its onset, did not produce differences in lipreading level. This could be good news for the professionals dedicated to intervention in oral speech for deaf people, because it allows them to focus their efforts on the variables in which they can intervene with from the educational system (early training, intensity and quality of training, etc.).

In conclusion, the study carried out is of twofold interest in the field of attention to the educational needs of people with hearing discapacity. On the one hand, it clears the way to new lines of investigation of lipreading as it has detected a series of variables whose possible influence could elucidate future studies of this topic. On the other hand, its results lead to practical consequences for the education of deaf people. If our goal is for these people to develop autonomously and successfully in our society, then to achieve a good mastery of lipreading is one of the key pieces. To achieve this good mastery, the following are necessary:

1. An adequate educational level in students with hearing discapacity. One can only lipread what one already knows and, therefore, it is just as important to develop good lipreading as an adequate conceptual development. To achieve this, it is sometimes necessary to resort to alternative or complementary systems to oral speech. Among such systems, sign language should not be ruled out, as it has been proven to be, at least, innocuous for lipreading.

2. Without contradicting the above, we must expose these students to oral speech, fulfilling all the rules to facilitate their perception (directly facing them when speaking, speaking at a short distance, vocalizing clearly but not exaggerating, etc.).

3. Improvement of the degree of deaf people's speech intelligibility because, according to these results, this variable has an important impact on lipreading. This datum leads us to suspect that people with hearing discapacity resort to their own articulation to discriminate the language they perceive on another person's lips.

4. As far as possible, to seek support for lipreading to make it more effective. Many studies support the usefulness of the cued speech for this purpose (see Torres \& Ruiz, 1996, for an exhaustive review).

To sum up, when the loss of hearing is such that it hinders or makes oral speech perception impossible, it is necessary to resort to lipreading, but this substitution, which is natural and instinctive in deaf people, requires exhaustive training and adequate instruments to overcome its limitations and ambiguities.

\section{References}

Alameda, J. R., \& Cuetos, F. (1995). Diccionario de frecuencias de las unidades lingüísticas del castellano. Oviedo: Servicio de Publicaciones de la Universidad de Oviedo.

Alegria, J. (1998). The origin and functions of phonological representations in deaf people. In C. Hulme \& R. M. Joshi (Eds.), Reading and spelling: Development and disorders (pp. 263-286). Mawah, NJ: Erlbaum.

Alegria, J., Charlier, B. L., \& Mattys, S. (1999). The role of lipreading and cued speech in the processing of phonological information in French-educated deaf children. European Journal of Cognitive Psychology, 11, 451-472.

Arnold, P., \& Köpsel, A. (1996). Lipreading, reading and memory of hearing and hearing-impaired children. Scandinavian Audiology, 25, 13-20.

Berger, K. W. (1972). Visemes and homophenous words. Teacher of the Deaf, 70, 396-399.

Bernstein, L. E., \& Auer, E. T. (2003). Speech perception and spoken word recognition. In M. Marschark \& P. E. Spencer (Eds.), Oxford handbook of deaf studies, language, and education (pp. 379-391). New York: Oxford University Press.

Bernstein, L. E., Demorest, M. E., \& Tucker, P. E. (1998). What makes a good speechreader? First you have to find one. In R. Campbell, B. Dodd \& D. Burnham (Eds.), Hearing by Eye II: Advances in the psychology of speechreading and auditoryvisual speech (pp. 211-227). East Sussex, UK: Psychology Press. 
Bernstein, L. E., Demorest, M. E., \& Tucker, P. E. (2000). Speech perception without hearing. Perception \& Psychophysics, 62, 233-252.

Campbell, R. (1997). Read the lips: Speculations on the nature and role of lipreading in cognitive development of deaf children. In M. Marschark, P. Siple, D. Lillo-Martin, R. Campbell \& V. S. Everhart (Eds.), Relations of language and thought: The view from sign language and deaf children (pp. 147-152). New York: Oxford University Press.

Campbell, R., \& Burden, V. (1994). The development of word coding skills in the born deaf: An experimental study of deaf school leavers. British Journal of developmental Psychology, 24, 331-350.

Cecilia Tejedor, A. (2000). Leer en los labios. Manual práctico para entrenamiento de la comprensión labiolectora. Madrid: CEPE.

Conrad, R. (1979). The deaf school child: Language and cognitive functions. London: Harper \& Row.

Dancer, J. (1994). A cross-sectional investigation of speechreading in adults: Effects of age, gender, practice, and education. Volta Review, 96, 31-40.

De Filippo, C. L. (1982). Memory for articulated sequences and lipreading performance of hearing-impaired observers. Volta Review, 31, 134-146.

Dodd, B. (1980). The spelling abilities of profoundly prelingually deaf children. In U. Frith (Ed.), Cognitive processes in spelling (pp. 423-440). New York: Academic Press.

Gómez Fernández, D. (1985). Prueba para la discriminación del estado de la discriminación audiemática en el hipoacúsico. CAUCE, Revista de Filología y su Didáctica, 8, 229-276.

González Cuenca, A. M. (1995). Revisión de los códigos y sistemas lingüísticos que pueden utillizarse para la comunicación con el niño sordo. Revista de Educación Especial, 19, 75-84.

Harris, M., \& Moreno, C. (2006). Speech reading and learning to read: A comparison of 8-year-old profoundly deaf children with good and poor reading ability. Journal of Deaf Studies and Deaf Education, 11, 189-201.

Justicia, F. (1995). El desarrollo del vocabulario. Diccionario de frecuencias. Granada (Spain): Universidad de Granada.

Kyle, F.-E., \& Harris, M. (2006). Concurrent correlates and predictors of reading and spelling achievement in deaf and hearing school children. Journal of Deaf Studies and Deaf Education, 11, 273-288.

Liberman, A. M., Cooper, F. S., Shankweiler, D. P., \& StuddertKennedy, M. (1967). Perception of the speech code. Psychological Review, 74, 431-461.

Ling, D. (1976). Speech and the hearing-impaired child: Theory and practice. Washington, D.C.: Alexander Graham Bell Association for the Deaf.

Lyxell, B. (1994). Skilled speechreading: A single case study. Scandinavian Journal of Psychology, 35, 212-219.

Lyxell, B., \& Rönnberg, J. (1989). Information processing skills and speech reading. British Journal of Audiology, 23, 339-347.

Lyxell, B., Rönnberg, J., \& Samuelsson, S. (1994). Internal speech functioning and speech-reading in deafened and normal hearing adults. Scandinavian Audiology, 23, 181-185.
Massaro, D. W. (1987). Speech perception by ear and eye. In B. Dodd \& R. Campbell (Eds.), Hearing by eye: The psychology of lip-reading (pp. 53-83). London / Hillsdale, NJ: Erlbaum.

Mogford, K. (1987). Lip-reading in the prelingually deaf. In B. Dodd \& R. Campbell (Eds.), Hearing by eye: The psychology of lip-reading (pp. 191-211). Hillsdale, NJ: Erlbaum.

Montgomery, A. A., \& Jackson, P. L. (1983). Physical characteristics of the lips underlying vowel lipreading performance. Journal of the Acoustical Society of America, 73, 2134-2144.

Nicholls, G.H., \& Ling, D. (1982). Cued speech and the reception of spoken language. Journal of Speech and Hearing Research, 25, 262-269.

Owens, E., \& Blazek, B. (1985). Visemes observed by hearing impaired and normal hearing adults viewers. Journal of Speech and Hearing Research, 28, 381-393.

Perelló, J., \& Tortosa, F. (1978). Sordomudez (3 ${ }^{\text {rd }}$ ed.). Barcelona: Editorial Científico Médica.

Rönnberg, J. (1995). What makes a skilled speechreader? In G. Plant \& K. Spens (Eds.), Profound deafness and speech communication (pp. 393-416). London: Whurr.

Rönnberg, J., Samuelsson, S., \& Lyxell, B. (1998). Conceptual constraints in sentence-based lipreading in the hearing-impaired. In R. Campbell, B. Dodd \& D. Burnham (Eds.), Hearing by eye ii: Advances in the psychology of speechreading and auditory-visual speech (pp. 143-153). East Sussex, UK: Psychology Press.

Samuelsson, S., \& Rönnberg, J. (1991). Script activation in lipreading. Scandinavian Journal of Psychology, 32, 124-143.

Samuelsson, S., \& Rönnberg, J. (1993). Implicit and explicit use of scripted constraints in lipreading. European Journal of Cognitive Psychology, 5, 201-233.

Santana, R., \& Torres, S. (2000). Las representaciones fonológicas en el sordo: papel de la palabra complementada en su desarrollo y uso. Revista de Logopedia Foniatría y Audiología, XX, 6-15.

Schwartz, J.-L., Berthommier, F., \& Savariaux, C. (2004). Seeing to hear better: Evidence for early audio-visual interactions in speech identification. Cognition, 93, 69-78.

Silvestre, N., \& Laborda, C. (1998). Adquisición del lenguaje oral en el alumnado con sordera prelocutiva. In N. Silvestre (Ed.), Sordera, comunicación y aprendizaje (pp. 27-41). Barcelona: Masson.

Tillberg, I., Rönnberg, J., Svärd, I., \& Ahlner, B. (1996). Audiovisual tests in a group of hearing-aid users: The effects of onset age, handicap age, and degree of hearing loss. Scandinavian Audiology, 25, 267-272.

Torres, S., \& Ruiz, M. J. (1996). La palabra complementada. el modelo oral complementado: introducción a la intervención cognitiva en logopedia. Madrid: CEPE.

Torres, S., Urquiza, R., \& Santana, R. (1999). Deficiencia auditiva. Guía para profesionales y padres. Málaga: Aljibe.

Woodward, M. F., \& Barber, C. G. (1960). Phoneme perception in lipreading. Journal of Speech and Hearing Research, 3, 212-222.

Received April 25, 2006

Revision received March 19, 2008

Accepted April 5, 2008 


\section{APPENDIX 1}

\section{Level 1 Recording Sheet}

Level 1 Lipreading: Words of different length and with different phonemes

\begin{tabular}{|c|c|c|c|c|c|c|}
\hline \multirow{2}{*}{ Print } & \multicolumn{4}{|c|}{ Image } & \multirow{2}{*}{ Type of error } & \multirow{2}{*}{ Nr. of hits } \\
\hline & 1 & 2 & 3 & 4 & & \\
\hline Practice print & joya & cuaderno & bellota & aceituna & $1 \rightarrow$ & \\
\hline Practice print & libro & paraguas & canario & cafetera & $1 \rightarrow$ & \\
\hline Print 1 & pan & teléfono & cronómetro & huevo & $1 \rightarrow$ & \\
\hline Print 2 & leche & calculadora & plátano & naranja & $1 \rightarrow$ & \\
\hline Print 3 & piso & alfombra & lámpara & maceta & $1 \rightarrow$ & \\
\hline Print 4 & moto & pintura & galleta & cadena & $1 \rightarrow$ & \\
\hline Print 5 & luna & helado & bicicleta & estatua & $1 \rightarrow$ & \\
\hline Print 6 & boca & pueblo & cuaderno & mazapán & $1 \rightarrow$ & \\
\hline Print 7 & queso & puerta & guisante & mariposa & $1 \rightarrow$ & \\
\hline Print 8 & choza & ventana & cacerola & juguete & $1 \rightarrow$ & \\
\hline Print 9 & dedo & muñeco & cuadro & salchicha & $1 \rightarrow$ & \\
\hline Print 10 & foto & brasero & maquillaje & pasador & $1 \rightarrow$ & \\
\hline Print 11 & gamba & mejillón & pendiente & espárrago & $1 \rightarrow$ & \\
\hline Print 12 & jamón & chocolate & plumero & bolígrafo & $1 \rightarrow$ & \\
\hline Print 13 & lobo & oveja & pulsera & chuleta & $1 \rightarrow$ & \\
\hline Print 14 & llave & garbanzo & tortuga & tenedor & $1 \rightarrow$ & \\
\hline Print 15 & manta & colgante & cuchillo & orquídea & $1 \rightarrow$ & \\
\hline Print 16 & nueve & babero & ajedrez & cerveza & $1 \rightarrow$ & \\
\hline Print 17 & moño & pie & anillo & ordenador & $1 \rightarrow$ & \\
\hline Print 18 & puño & refresco & chorizo & chirimoya & $1 \rightarrow$ & \\
\hline Print 19 & oro & lámpara & cuchara & juego & $1 \rightarrow$ & \\
\hline Print 20 & reyes & pasador & alfombra & fregona & $1 \rightarrow$ & \\
\hline Print 21 & sello & carpeta & aceite & astronauta & $1 \rightarrow$ & \\
\hline Print 22 & taza & cepillo & maleta & chimenea & $1 \rightarrow$ & \\
\hline Print 23 & zapato & caja & anís & vela & $1 \rightarrow$ & \\
\hline
\end{tabular}




\section{APPENDIX 2}

\section{Level 2 Recording Sheet}

Level 2 Lipreading: Words of the same length and with different phonemes

\begin{tabular}{|c|c|c|c|c|c|c|}
\hline \multirow{2}{*}{ Print } & \multicolumn{4}{|c|}{ Image } & \multirow{2}{*}{ Type of error } & \multirow{2}{*}{ Nr. of hit } \\
\hline & 1 & 2 & 3 & 4 & & \\
\hline Practice print & muro & lápiz & caja & carro & $1 \rightarrow$ & \\
\hline Practice print & disco & plancha & cable & pesca & $1 \rightarrow$ & \\
\hline Print 1 & lata & pera & piso & cazo & $1 \rightarrow$ & \\
\hline Print 2 & leña & foto & barco & horno & $1 \rightarrow$ & \\
\hline Print 3 & lomo & zumo & pelo & gafas & $1 \rightarrow$ & \\
\hline Print 4 & oso & ala & ajo & uva & $1 \rightarrow$ & \\
\hline Print 5 & luna & pollo & rama & seta & $1 \rightarrow$ & \\
\hline Print 6 & vaso & mesa & paño & leche & $1 \rightarrow$ & \\
\hline Print 7 & carta & cerdo & nave & dulce & $1 \rightarrow$ & \\
\hline Print 8 & choco & lata & niña & tinte & $1 \rightarrow$ & \\
\hline Print 9 & dedo & lápiz & cable & lazo & $1 \rightarrow$ & \\
\hline Print 10 & faro & cazo & queso & pata & $1 \rightarrow$ & \\
\hline Print 11 & gato & pico & león & plancha & $1 \rightarrow$ & \\
\hline Print 12 & jamón & mano & leche & café & $1 \rightarrow$ & \\
\hline Print 13 & licor & turrón & bombón & miel & $1 \rightarrow$ & \\
\hline Print 14 & yema & vino & caja & piña & $1 \rightarrow$ & \\
\hline Print 15 & moto & olla & gato & dátil & $1 \rightarrow$ & \\
\hline Print 16 & nudo & pasta & gafas & joya & $1 \rightarrow$ & \\
\hline Print 17 & puño & choza & falda & reloj & $1 \rightarrow$ & \\
\hline Print 18 & pato & falda & queso & niño & $1 \rightarrow$ & \\
\hline Print 19 & loro & dulce & pera & vela & $1 \rightarrow$ & \\
\hline Print 20 & rosa & cable & lazo & café & $1 \rightarrow$ & \\
\hline Print 21 & silla & licor & mono & balón & $1 \rightarrow$ & \\
\hline Print 22 & taza & sello & gamba & boca & $1 \rightarrow$ & \\
\hline Print 23 & zumo & palo & gata & gorro & $1 \rightarrow$ & \\
\hline
\end{tabular}




\section{APPENDIX 3}

Level 3 Recording Sheet

Level 3 lipreading: Words of same length and similar phonemes

\begin{tabular}{|c|c|c|c|c|c|c|c|c|}
\hline \multicolumn{4}{|c|}{ Image } & \multirow{2}{*}{\multicolumn{4}{|c|}{ Type of error }} & \multirow{2}{*}{ Nr. of hits } \\
\hline 1 & 2 & 3 & 4 & & & & & \\
\hline pico & rico & chico & cinco & $1 \rightarrow$ & $2 \rightarrow$ & $3 \rightarrow$ & $4 \rightarrow$ & \\
\hline coche & noche & ponche & broche & $1 \rightarrow$ & $2 \rightarrow$ & $3 \rightarrow$ & $4 \rightarrow$ & \\
\hline pala & polo & pela & pila & $1 \rightarrow$ & $2 \rightarrow$ & $3 \rightarrow$ & $4 \rightarrow$ & \\
\hline tela & tala & tila & Tula & $1 \rightarrow$ & $2 \rightarrow$ & $3 \rightarrow$ & $4 \rightarrow$ & \\
\hline poro & pero & puro & paro & $1 \rightarrow$ & $2 \rightarrow$ & $3 \rightarrow$ & $4 \rightarrow$ & \\
\hline muro & mero & moro & miro & $1 \rightarrow$ & $2 \rightarrow$ & $3 \rightarrow$ & $4 \rightarrow$ & \\
\hline vino & pino & fino & chino & $1 \rightarrow$ & $2 \rightarrow$ & $3 \rightarrow$ & $4 \rightarrow$ & \\
\hline casa & gasa & pasa & masa & $1 \rightarrow$ & $2 \rightarrow$ & $3 \rightarrow$ & $4 \rightarrow$ & \\
\hline chilla & silla & villa & pilla & $1 \rightarrow$ & $2 \rightarrow$ & $3 \rightarrow$ & $4 \rightarrow$ & \\
\hline ducha & lucha & hucha & trucha & $1 \rightarrow$ & $2 \rightarrow$ & $3 \rightarrow$ & $4 \rightarrow$ & \\
\hline nada & napa & narra & nata & $1 \rightarrow$ & $2 \rightarrow$ & $3 \rightarrow$ & $4 \rightarrow$ & \\
\hline fuego & zueco & hueco & cuenco & $1 \rightarrow$ & $2 \rightarrow$ & $3 \rightarrow$ & $4 \rightarrow$ & \\
\hline gota & jota & bota & sota & $1 \rightarrow$ & $2 \rightarrow$ & $3 \rightarrow$ & $4 \rightarrow$ & \\
\hline joya & goya & boya & olla & $1 \rightarrow$ & $2 \rightarrow$ & $3 \rightarrow$ & $4 \rightarrow$ & \\
\hline lave & llave & nave & ave & $1 \rightarrow$ & $2 \rightarrow$ & $3 \rightarrow$ & $4 \rightarrow$ & \\
\hline lloro & loro & moro & oro & $1 \rightarrow$ & $2 \rightarrow$ & $3 \rightarrow$ & $4 \rightarrow$ & \\
\hline nata & lata & mata & rata & $1 \rightarrow$ & $2 \rightarrow$ & $3 \rightarrow$ & $4 \rightarrow$ & \\
\hline piña & pila & pita & pipa & $1 \rightarrow$ & $2 \rightarrow$ & $3 \rightarrow$ & $4 \rightarrow$ & \\
\hline pisa & misa & visa & risa & $1 \rightarrow$ & $2 \rightarrow$ & $3 \rightarrow$ & $4 \rightarrow$ & \\
\hline pera & perra & pela & peña & $1 \rightarrow$ & $2 \rightarrow$ & $3 \rightarrow$ & $4 \rightarrow$ & \\
\hline asa & hacha & ata & ala & $1 \rightarrow$ & $2 \rightarrow$ & $3 \rightarrow$ & $4 \rightarrow$ & \\
\hline zorro & corro & gorro & forro & $1 \rightarrow$ & $2 \rightarrow$ & $3 \rightarrow$ & $4 \rightarrow$ & \\
\hline
\end{tabular}

Total score of Level 3 (maximum Nr. of hits $=80$ )

Total score of isolated words (Levels 1, 2, and 3)

Observations: 